\title{
Measuring Impact of Kazi \& Kazi Tea Estate Limited, Panchagarh-An Organic Garden in Bangladesh
}

\author{
Md. Shafiqul Islam ${ }^{1}$ \\ Assistant Professor \\ Center for Sustainable Development, University of Liberal Arts Bangladesh, Dhaka, Bangladesh
}

\begin{abstract}
Measuring impact of Kazi \& Kazi Tea Estate (KKTE) was conducted over the period of four months starting from May, 2011 to August 2011. This survey was conducted exclusively in the KKTE operating areas covering 3 Upazillas of Panchagarh district. The main objective of this study was to make an assessment on impact of KKTE within its vicinity in Panchagarh. In order to get qualitative information data were collected through 20 FGDs with each respective respondents (Two FGDs from each unit, one FGD with the KKTE workers and another one FGD with outside KKTE people) to get real picture of the study areas. Total 50 respondents were interviewed through structured KII formats (5 persons from each unit: One Govt. Official, one UP member/chairman, one KKTE regular staff, one KKTE male worker and one KKTE female worker). Most of the respondents were mentioned that KKTE is serving for the population by creating employment opportunity, creating knowledge platform for organic farming, and ensuring eco-friendly farming activities. Women are getting job/work priority in KKTE at the same time disable, ethnic and minority is getting special priority during selection of workers. KKTE is also performing lot of social activities reported by the respondents from all categories including financial support to the meritorious poor students, sport goods to the youth clubs, school, college and madrasha, Donation to the mosques, clubs, schools and colleges. KKTE is also playing great role in raising awareness on health \& hygiene among the workers and community people through training and hardware support likely distribution of sanitary latrine among the community people free of cost and training on several issues. Community people are the major stakeholders of KKTE getting benefits both ways either directly or indirectly through employment, supplying various products including bamboo, straw, baskets, top soil etc. Respondents were mentioned that KKTE is playing great role in environmental conservation by planting trees, organic farming and using renewable energy. KKTE is offering diverse products in the local to national and even crossing international boundaries including tea, tulshi tea, lemon grass, mint tea, ghee, honey and sweets. KKTE is emitting less carbon by using nature friendly inputs. KKTE is using renewable energy and promoting for communal uses including solar energy and bio-gas plant. Chemical contaminations from others conventional farming are the main problem for KKTE. On the other hand, lack of workers during peak (plucking season) seasons are the common problem for KKTE. It is recommended that if the perceived problem could be solved by setting up of more tea processing industries, competitive markets at the grass roots for tea leaves, supply of natural gas and resolving problems like power crisis could accelerate the production of tea. KKTE needs to initiate more social activities in the wider scale in the diverse field for the well being of the community people.
\end{abstract}

\section{Introduction}

Impact studies may deal with a variety of interventions-be they social, economic, political or other-wise in different societies. The concept impact in itself is very vague and all-encompassing; it can mean anything and everything. Impact may be economic, social, political, environmental, technological or institutional and a host of other things. A simple definition of impact is that it is the change brought about by a certain action. In the context of assessment of development interventions it is usual to define impact as the long-term and sustainable changes brought by a given intervention in the lives those affected by the project (CDR,1993,P.3). Impact is usually seen as the last link in the project chain: input-output-outcome-impact (cfr.Oakley et al.,p.33). According to Vivek definition, Social impacts are impacts of developmental intrusions on human settlements. Such impacts not only need to be identified and measured but also need to be managed in such a way that the positive externalities are puffed up and the depressing ones minimized. Social impacts are not only diverse but affect different population groups, individuals and household types in a different manner. Additionally the same economic impact (for example an income cut of 10 per cent) can affect households or individuals with different characteristics in very divergent ways [1]. Another definition described by Barrow that 'social impact' may be defined as an adaptation on the part of a social system to external agents of change and/or endogenous change. Another definition might be 'the social consequences of actions, including change to norms, beliefs, perceptions, values, etc [2]. 
Frank Vanday has mentioned that social impact assessment includes the process of analyzing, monitoring and managing the intended and unintended social consequences, both positive and negative, of planned interventions (policies, programs, plans, projects) and social change processes involved by those interventions [3]. Social business is not a new concept in the world. It is widely known to all. Professor Yunus has described in his book "Creating a World Without Poverty" how partnership worked with some of the world's most visionary business leaders has launched the world's first purposely designed social businesses [4].

In spite of this, by way of is the case in some other parts of the globe[5,6,7,8],greater attention is still being given in South Africa to broader environmental issues rather than attempting to balance the focus to include social concerns[9]. Most of the organizations have social, environmental and economic impacts that have an effect on people, their communities and the environment for the better. They may be a social enterprise, a private business, a voluntary organization or a government initiative. Some may be large... and others run by a very small group of people. The measure of impact is very much important for improved program management including effective planning, monitoring, evaluation and increased understanding of the work. It also enhanced attention to the social value created by the business or organization or company. There are four main elements needed to measure social value creation which starts with inputs, outputs, outcomes and impacts [10].

In an attempt to alleviate this problem the social impact assessors applied a multifaceted approach and used triangulation $[11,12,13,14$, and 15] as a technique when collecting data. In this manner, they attempted to transcend the technocratic-participatory divide in social assessments identified by involving certain community representatives in the execution of the research [16].

Kazi \& Kazi Tea Estate Ltd. (KKTE) is a private limited company and only organic garden in Bangladesh, situated at the northernmost distant district of Panchagarh in Bangladesh, $50 \mathrm{~km}$ south of Darjeeling, this for-profit private enterprise, does not rely on contributions for its operations and instead wholly reinvests profits into the company [17]. Kazi \& Kazi Tea Estate limited is operating its activities in Panchagarh district including organic farming diversities and social activities. Kazi \& Kazi Tea Estate is the pioneer in organic tea plantation in Bangladesh. KKTE is also a combined garden, having dairy, herbal plantation and other agricultural products such as rice, wheat, corn, oilseed, fruits, pulses and vegetables, all are grown organically.

Lot of small growers, holders and tea estates has been established in the Tetulia upazilla under Panchagarh district, the northwest region and along boarder of India. In 2011 there were around 274 small growers (Registered 261 and unregistered 13),16 smallholders ( Registered 15 and unregistered 1) and 20 tea gardens ${ }^{1}$ (Registered 9 unregistered 11). The total area of these tea farms and gardens were 968.48 hectares [18]. According to Bangladesh Tea Board (BTB) report, presently, over 7,000 skilled and unskilled workers, mostly women, have been working in 285 tea gardens, including 9 big estates, 15 small holders (medium-size) and 261 small growers' gardens set up on more than 1,998.44 hectares of land in Tetulia and its surrounding areas. Of them nearly 2,300 workers, mostly women, are working alone at the colossal Kazi and Kazi Tea Estate (KKTE) at Tetulia which has earned reputation in both national and international markets by producing, processing and marketing the famous and most popular Organic Tea and earning foreign exchange[19]. The main objective of this study was to make an assessment on impact of KKTE within its vicinity in Panchagarh.

\section{Methodology}

Ten study sites were selected from Panchagarh district. Each site contained an organic tea production facility whose management was cooperating with other members of the study team. This study was conducted over the period of four months starting from May, 2011 to August 2011. In this study random sampling was followed in selecting respondents for Focus Group Discussions (FGDs) and Key Informant Interviews (KIIs) from study sites. The survey was based on following criteria: In order to get qualitative information data were collected through 20 FGDs with each respective respondents (Two FGDs from each unit, one FGD with the KKTE workers and another one FGD with outside KKTE people) 12 participants were in each FGD of which 6 participants male and 6 participants female to get real picture of the study areas. Total 50 respondents were interviewed through structured KII formats (5 persons from each unit: One Govt. Official, one UP member/chairman, one KKTE regular staff, one KKTE male worker and one KKTE female worker)

III. Results

Table: 1 Respondent's analysis by sex, age, education, occupation and income

\begin{tabular}{|c|c|c|c|c|c|c|c|}
\hline Type & \multicolumn{2}{|c|}{ Sex } & Age & Education & Househol & Income & Occupation \\
\hline & Male & $\begin{array}{l}\text { Fema } \\
\text { le }\end{array}$ & & & $\begin{array}{l}\mathrm{d} \\
\text { members }\end{array}$ & & \\
\hline $\begin{array}{l}\text { Govt } \\
\text { Officials/ } \\
\text { UP } \\
\text { members }\end{array}$ & $\begin{array}{l}16(80 \\
)^{\mathrm{a}}\end{array}$ & $4(20)^{a}$ & $\begin{array}{l}47 \\
(30- \\
65)^{\mathrm{b}}\end{array}$ & $\begin{array}{l}\text { Primary- } \\
3(15) \\
\text { Secondary- } \\
13(65)\end{array}$ & $7(3-13)^{b}$ & $\begin{array}{l}21750(3,000- \\
1,20,000)^{\mathrm{b}}\end{array}$ & $\begin{array}{l}\text { UP-10(50) } \\
\text { Service- } \\
10(50)^{\mathrm{a}}\end{array}$ \\
\hline
\end{tabular}




\begin{tabular}{|c|c|c|c|c|c|c|c|}
\hline $\mathrm{N}=20$ & & & & $\begin{array}{l}\text { University- } \\
4(20)\end{array}$ & & & \\
\hline $\begin{array}{l}\text { Regular } \\
\text { staff } \\
\mathrm{N}=10\end{array}$ & $\begin{array}{l}10(10 \\
0)^{\mathrm{a}}\end{array}$ & & $\begin{array}{l}35 \\
(27- \\
48)^{\mathrm{b}}\end{array}$ & $\begin{array}{l}\text { Secondary- } \\
5(10) \\
\text { University- } \\
4(40) \\
\text { Others- } \\
1(10)\end{array}$ & $6(3-13)^{b}$ & $\begin{array}{l}15344(3600- \\
35000)^{\mathrm{b}}\end{array}$ & $\begin{array}{l}\text { Service- } \\
10(100)^{a}\end{array}$ \\
\hline $\begin{array}{l}\text { Workers } \\
\mathrm{N}=20\end{array}$ & $\begin{array}{l}10(50 \\
)^{\mathrm{a}}\end{array}$ & $\begin{array}{l}10(50 \\
)^{\mathrm{a}}\end{array}$ & $\begin{array}{l}36 \\
(21- \\
60)^{\mathrm{b}}\end{array}$ & $\begin{array}{l}\text { Illiterate- } \\
6(30) \\
\text { Primary- } \\
2(10) \\
\text { Secondary- } \\
11(55) \\
\text { University- } \\
1(5)\end{array}$ & $6(2-12)^{b}$ & $\begin{array}{l}5997(600- \\
25000)^{\mathrm{b}}\end{array}$ & $\begin{array}{l}\text { Worker } \\
20(100)^{\mathrm{a}}\end{array}$ \\
\hline
\end{tabular}

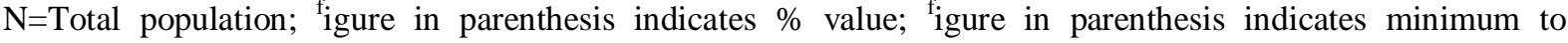
maximum

Analyzing sample respondents, data showed us that $80 \%$ respondents were male from government officials and UP members. On the other hand, $100 \%$ were male from staff and $50 \%$ respondents were female from workers. The average age was 35 years with the range from minimum 27 to 48 years among the staff and 21 to 60 years among the workers. The government officials and UP members were in between 30 to 65 years old. Among the governmental officials and UP members $65 \%$ respondents were hold secondary education followed by university degree and primary education. On the other hand, $40 \%$ respondents were possess university degree among regular staff and 55\% respondents were belongs to secondary education among the workers.

\section{Economic Impact}

Community change and livelihood development: As compared to past, the population characteristic has tainted over time. Both KKTE people and outside people agreed that positive change has occurred after KKTE intervention. The noteworthy changes are listed down: Population has increased in numbers and density; Unwaged has engaged in several occupations; The education rate has increased (Especially adult education); Remarkable income has increased in the environs of KKTE; Less pollution due to organic farming activities; Women empowerment (women is getting preferences in the work; Few were switching occupation from agriculture to business; Livelihood improvement; Local market establish and development; Area development; Decreased rate of unemployment; Poverty reduction; Better communication \& road infrastructure (Connecting road).Community people prefer present situation for community progress but they want more improvement in the near future. The local community people has participated in this progress willingly and accepted gladly. $25 \%$ respondents answered that it is an organic garden and produce organic products involving community people. $15 \%$ mentioned that environment friendly garden and good organization. Only 5\% respondents were mentioned that they have no idea on it

Community services: Basically KKTE is rendering various types of services for community development including staff time volunteering, free treatment, green energy (biogas/solar), sport goods \& safe latrine distribution, adult education, computer training, distribution of seeds and saplings. 60 persons were received training on computer application and 667 families received safe latrines free of cost. KKTE has created great impacts by distributing sport goods (Foot ball, cricket set, volley ball, carom and chese board) towards the youth. At the same time KKTE has donated BDT 95000 among the disadvantaged community people in 2010. Among the workers, 95\% respondents were mentioned that KKTE is serving for community people of whom $75 \%$ were agreed that KKTE has created employment opportunity for the community people followed by $10 \%$ for knowledge creation on health and hygiene and $10 \%$ for friendly environment.

Role of KKTE in employment creation: Respondents were mentioned that women are getting preferences in KKTE during selection of workers and frontline staffs. Communities are welcoming such issues and gladly accepted it for empowering women and ethnic people. Everyone from community accepted it positively. No special facilities were setup for the women still now. KKTE was created employment opportunities for the rural poor and distressed people. As per survey result, 60\% respondents were mentioned that KKTE has created employment opportunity for local community people directly and $25 \%$ respondents were mentioned that KKTE has engaged community people as workers or suppliers indirectly (Fig 1). 


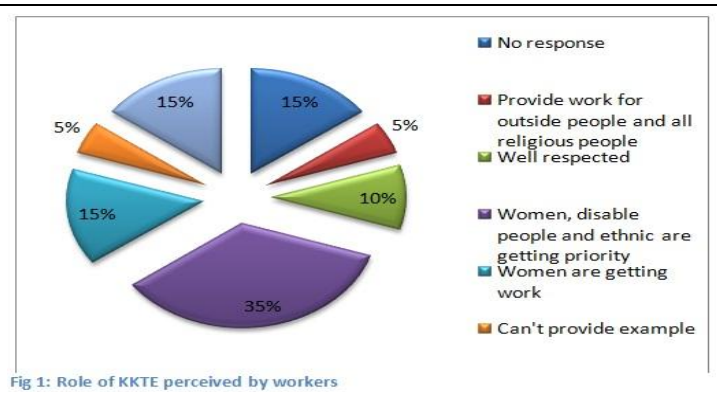

KKTE stakeholders: Community people are the main stakeholder of KKTE. They were benefitted either working with KKTE directly or by engaging with KKTE as suppliers by supplying various inputs including sand, top soil for nursery, stone for the construction works, dairy feed, straws, bamboo and other materials for farming activities. The following were recognized as the stakeholders: community people; who work in the KKTE; suppliers \& staff. As per respondent's opinion community people who are working at KKTE are the major stakeholders whereas, the outside KKTE people mentioned that community is the main stakeholders as because they lead their livelihood working with KKTE. Community is the major stakeholders. $65 \%$ respondents were identified stakeholders and rest of the respondents has no idea KKTE stakeholders (Fig 2). 15\% respondents were mentioned that community people are main stakeholders followed by workers, suppliers and motivated to organic farming (tea cooperatives).

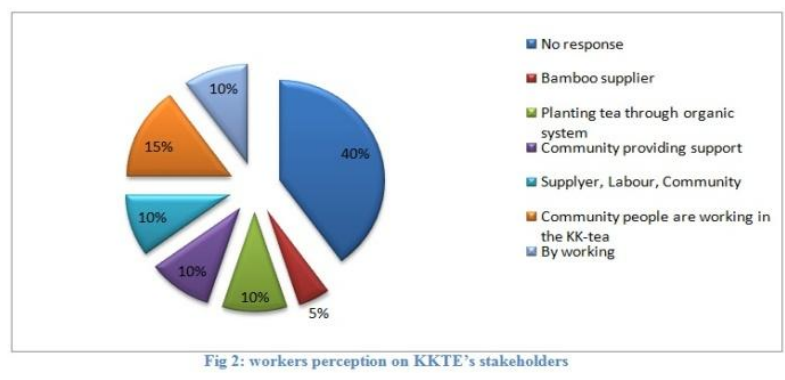

55\% respondents were agreed that community need them for cooperation and assistance followed by backward linkage and social commitment.

\section{Environmental Impact}

$100 \%$ respondents opined that KKTE is doing nature friendly farming activities of whom $40 \%$ agreed for use of organic inputs, $15 \%$ for avoiding chemicals, $15 \%$ for planting lot of trees and $10 \%$ for organic systems(Fig 3).

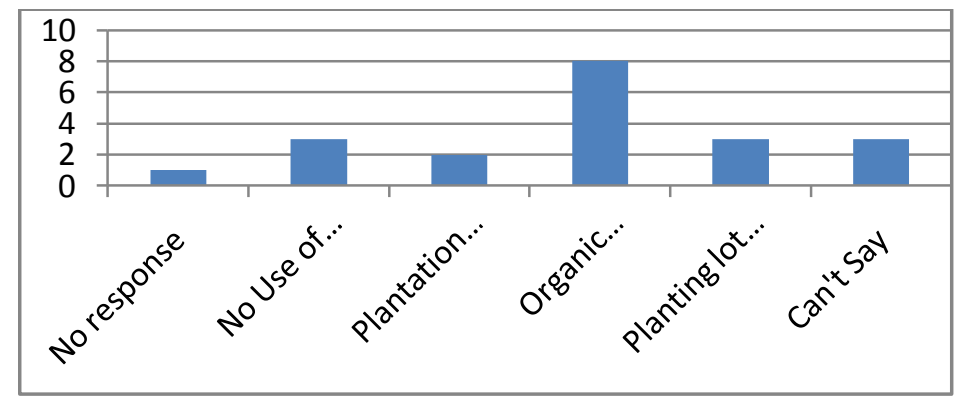

Figure 3: KKTE's nature friendly activities

Changes in Physical Infrastructure -- greening land and Environment: Greening was perceived as the prevalent cultivating practice in Panchagarh, Bangladesh. It was attributed to diverse and complex motivations that include: brought fallow lands under green cultivation; land conversion from unused to better utilizations; land conversion from traditional use to tea plantations. 90\% respondents were mentioned that KKTE is playing great role in environmental conservation by planting trees, organic farming and using renewable energy. Community can take part in the environmental conservation by planting trees in their homesteads $(30 \%)$, adopting organic farming practices (20\%), and avoiding chemicals (Fig 4). 


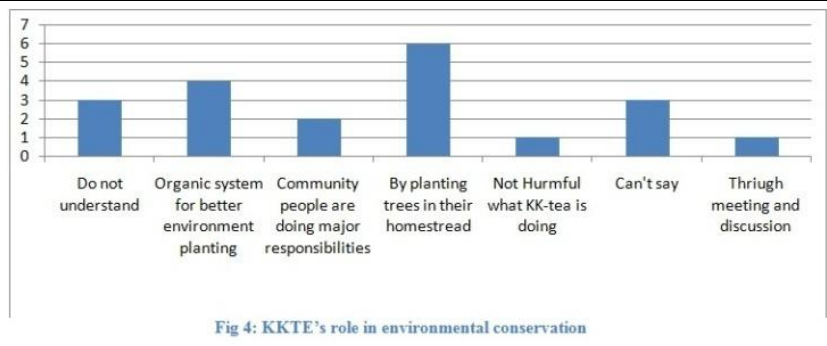

Products and farming diversity of KKTE: KKTE is offering diverse products in the local to national and even crossing international boundaries. 55\% respondents were recognized tea, sweet, ghee and honey another $20 \%$ were recognized tea, tulshi tea, lemon grass, mint tea, ghee, honey and sweets. Another 5\% were identified vegetables, rice additionally mentioning high quality and purity (Fig 5).

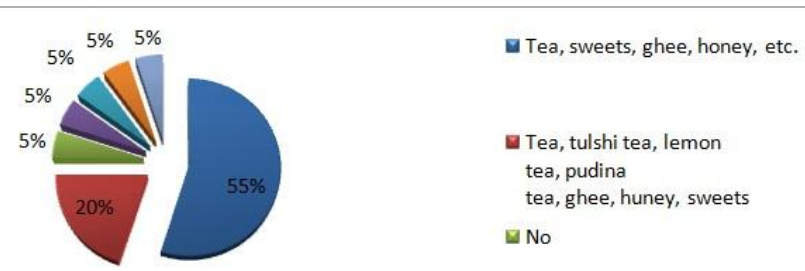

Fig 5: Product diversity of KKTE

Farming activities and carbon emission: $75 \%$ respondents were mentioned that KKTE is emitting less carbon (Fig 6) by using nature friendly inputs (20\%), planting lot of tress (20\%), using solar and bio-gas (20\%) and reduce carbon emission $(20 \%)$.

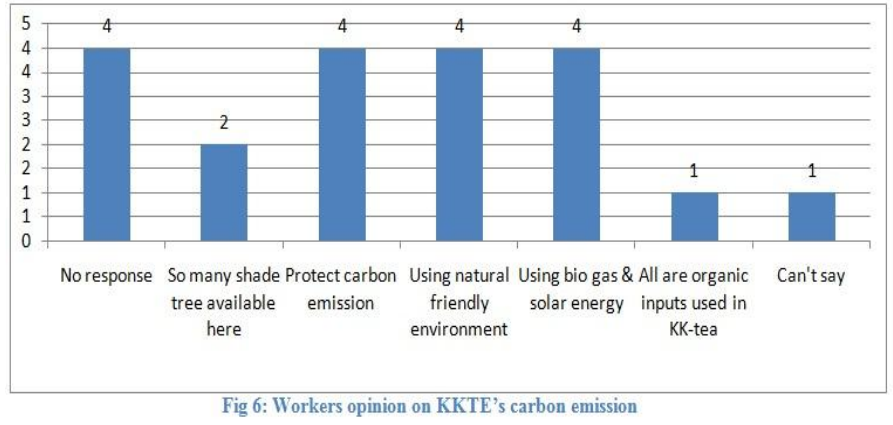

Role of KKTE in renewable energy: Only $25 \%$ respondents were mentioned that KKTE is serving to community for renewable energy and farming of whom $15 \%$ told that KKTE is providing community based biogas plant (Fig 7).

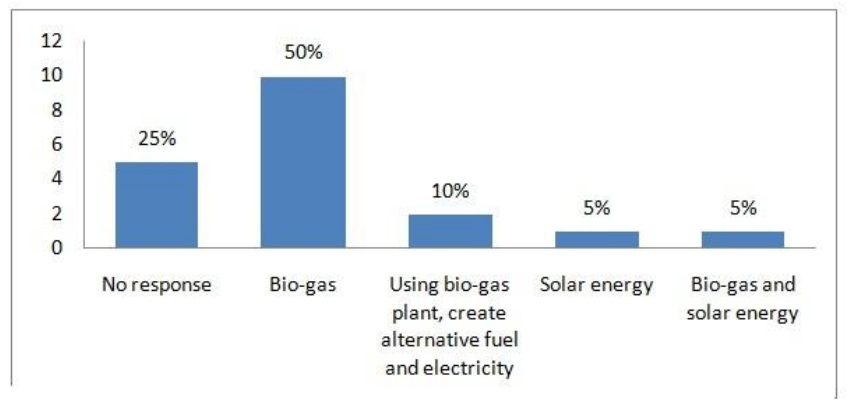

Fig 7: Role of KKTE in renewable energy from workers point of view 


\section{SOCIAL IMPACT}

$50 \%$ respondents were mentioned that KKTE is performing social activities by providing training on organic farming (20\%), donating to mosque, madrasha (15\%), distribution of safe latrine free of cost $(15 \%)$, training on adult education (5\%) and providing financial support to the poor and meritorious students (5\%).

KKTE in youth development: KKTE is doing youth development activities in its surrounding areas. 35\% respondents were able to tell about youth development activities likely distribution of sports goods (10\%), training on computer (10\%), donation of books (5\%) and adult education (5\%).

KKTE in adult education: 25\% respondents were mentioned that KKTE is providing adult education for the workers in the selected division and this to ensure education to all (15\%), forming better community (10\%), and literate the people $(5 \%)$.

Role of KKTE in health care: $55 \%$ respondents were mentioned that KKTE is providing free treatment with medicine free of cost. $15 \%$ respondents were mentioned that KKTE is arranging training on health and hygiene for the workers followed by distribution of safe latrine (10\%) and providing soap and detergent (5\%).

Women in social activities: Only $45 \%$ respondents were mentioned that women are getting preferences in social activities by flexibility in working hours (20\%). $75 \%$ respondents were mentioned simply no.

Donation to club/institution/individual: $65 \%$ respondents were mentioned that KKTE is donating to the club, institution or individual. $30 \%$ respondents were told that regular donations go to mosque and $25 \%$ were mentioned that donations go the clubs.

KKTE suppliers (Supply linkage): The local community people have developed relationship with KKTE by supplying a range of goods and materials directly. The following goods or materials were supplied by the community people ranging from (70 to 100\%) including Bamboo; Straw; Rope; Basket; top soil for nursery; Sand; Stone (building materials) and cow dung. 75\% respondents were mentioned that KKTE has selected suppliers from local community to ensure regular supplies of inputs. 50\% respondents were told that the local suppliers are supplying various materials including bamboo, straw and cow dung. Among the respondents 15\% were told about bamboo followed by straw and cow dung.

\section{Human Resources Development}

KKTE has provided both spot training and in house training for the staff and workers in regular basis for their skill development in relation to organic farming activities, technical skill development and motivational training. 30 regular staffs were trained on different fields by spending BDT 1,30,000. Around 476 Daily laborers were also received spot training for their skill development in the field of compost preparations, mulching, plucking, pest management and personal health management and awareness rising in health and hygiene.

Promotion opportunity in KKTE: Only 10\% respondents were mentioned that KKTE is promoting or regularizing the workers and giving yearly increment. $85 \%$ respondents were absent to the answer.

Service benefits of KKTE: $85 \%$ respondents were mentioned that bonus is the only service benefit and 5\% were mentioned that may be permanent in KKTE. Only $10 \%$ respondents were mentioned that yet not get any benefit from KKTE.

Medical insurance or grants: Only 25\% respondents were mentioned that KKTE has medical insurance policy (Got full medical cost) and 75\% respondents were mentioned that KKTE has no such policy.

Salary/wages in KKTE: 55\% respondents were mentioned that KKTE is not giving low salary or wages compare to others. On the other hand, 45\% respondents were mentioned that KKTE is providing low wages/salary compare to others especially mentioning very low salary/wages.

Written policy for worker recruitment: $90 \%$ respondents were mentioned that they never heard about the written workers recruitment policy of KKTE and 0nly 10\% were answered yes mentioning female will get preference in recruiting workers.

Incentives from KKTE: Only 20\% respondents were mentioned that they have received incentives from KKTE including promotion (25\%), salary/wages enhancement (15\%) and overtime (5\%). 
Workers Selection criteria : $30 \%$ respondents were mentioned that performance judgment is the main criteria (Fig 8) in selection workers, $25 \%$ respondents were mentioned that women, disables and minority are getting preferences in the selection process followed by no idea (15\%), all kinds of worker (10\%), not honored for qualification $(10 \%)$, no criteria $(5 \%)$ and no response $5 \%)$.

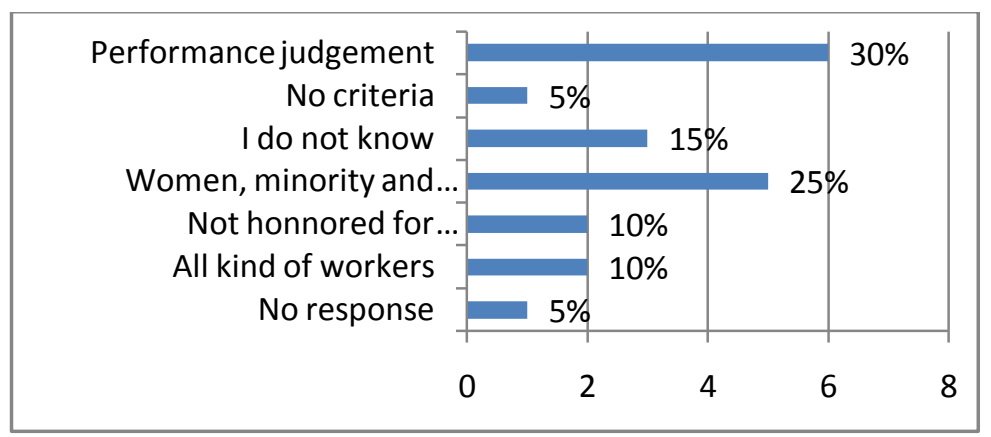

Fig 8: worker selection criteria from workers point of view

Community impact: The multifaceted impacts and benefits are either direct or indirect. The direct impacts are mostly economic, and reflected in enhanced income, and employment, and optimized expenditure pattern, surpluses, savings, and asset building. Most indirect impacts are related to the social and cultural aspects of life, which include, among others, such areas as education, health, women's status, modernization etc. These direct and indirect benefits together produce synergy in economic growth, poverty reduction, and human development.

Community relocation: KKTE has raised tea plantations in the remote areas and along the border of India. Even the lands were totally fallow over last decades. As a result no relocation efforts were made by the company.

Opportunity created by KKTE: KKTE has created new opportunities for the community people by creating employment opportunity, through adult education, forward backward linkage, computer training, innovative loan facilities and through renewable energy.

Perception of KKTE activities: KKTE people opined that it is an organic garden, risk free, no chemical hazards, uses only nature friendly inputs and friendly environment. Outside people reported that organic garden, no health hazards, friendly environment, no risks and use only nature friendly inputs.

Changes in land use pattern: Drastic change occurred in land use pattern after KKTE intervention. The community people are using cow dung in their fields avoiding or minimizing chemicals utilization. At the same time they are practicing green cultivation, fallow lands were brought under green cultivation. The benefit of organic farming is more production due to organized farming.

Perceptions of Health and hygiene and Changes in Daily Living Patterns: On a local scale, respondents mentioned nearly uniform agreement on the positive impacts of safe latrine distribution, free treatment facilities and training on personal health \& hygiene. Now people are more aware. They are using safe latrine and wash their hands with soap or ashes after evacuation. They also are washing their hands before eating and after going toilet. These impacts were identified in terms of distribution of hardware related to safe evacuation (safe latrines), dissemination of software on health and hygiene (training) and providing medicine free of cost. Respondents identified safe latrine as directly impacting their health and hygiene through safe evacuation and reduced disease occurrence intensity and changes in daily behavioral patterns. The behavioral pattern includes use sandal during evacuation, washing hands with soap or ashes after evacuation.

Effects on Physical Infrastructure -- Roads and communication: Many statements regarding impacts on rural roads were negative. Rural roads were perceived to be deteriorating as a result of difficult communication and remote rural transport. Maintenance costs were thus perceived to be higher, with consequent impacts on state and local tax structures. Many respondents were not knowledgeable about which institution was ultimately responsible for road maintenance and which funds were allotted to improve, maintain, and repair roads. Respondents were mentioned that rural connecting roads were repaired by KKTE in timely manner.

Impact on Employment: KKTE generates employment. The impact on employment was both direct and indirect. In Farming operations, an estimated persons are directly involved in farmlands. There has been direct employment of persons in the KKTE. More so, women in the households are involved more in household level 
income-generation activities. Unemployment rate is relatively low in the KKTE areas. In operation of KKTE, the highest employment opportunity has created in Panchagarh. Significant direct and indirect employment may result from the establishment of KKTE.

Effects on Household Income and Distribution: Respondents suggested positive impacts on household income and distribution of that income, in terms of the economic benefits of continued employment for local, community workers were of particular importance in Panchagarh. The economic efficiencies of providing a market for forward backward linkages were observed in all units. The usual income decrease which occurs every year towards winter time, due to the lack of agricultural activity, and in autumn due to lack of stone extraction in the study areas.

Changes in Occupational Opportunities: Respondents mentioned the positive impact of occupational opportunities in KKTE. Some suggested that the increasing newer tea factories resulted direct more employment. of greater impact and concern to respondents, however, was a perception that occupational opportunities were changing too fast and too significantly as a result of local, regional and national economic factors.

Access to healthcare services: KKTE regular frontline staffs, workers (both fixed and casual) are eligible for free treatment and subsidized Medicines as per KKTE policy and Health Care Services Program. At present KKTE have no compulsory health insurance policies for the staffs and workers. KKTE is not employed such policies, but hope to become employed such policies in the future.

Impact on gender \& Women's empowerment: KKTE has contributed to the positive development on women's socio-economic status. Farming has left a profound impact on women's mobility, participation in Income Generating Activities (IGAs), decision making, freedom in using income and savings, better utilization of credit, knowledge about gender inequality issues, household work plan according to convenience, changes in attitude in terms of reducing healthcare disparities, increase in overall years of schooling for both boys and girls, preference to send girls to schools, awareness of legal issues. It is against this context that KKTE should aim at changing rural women's overall living standard.

\section{Discussion}

A noticeable result of all these interviews is expression of a broad spectrum of impacts, concerns and opinions that form the image of KKTE facilities in Panchagarh. Indeed, this array of often contradictory perceptions is what drove the initiation and completion of the entire study of ecological and economic impacts of KKTE production.

Another common perception is that KKTE provides a market for organic quality produces. However, chemical farming leads monocultures, causing negative impacts on environment and soil fertility. Some of these contradictory perceptions can be resolved through this social impact study and the combined research results of the entire study on economic and ecological impacts of KKTE in Panchagarh. This report does not concentrate on providing a detailed description of community impacts. It rather takes the view that aggregated effects impacting on households and individuals constitute the basis for an overall community effect. Of course, among the phenomena mentioned throughout the report, economic and social phenomena take place at a community level, precisely where people live and work. Higher unemployment, lower income, increased poverty, lower economic activity, less consumption, all these and other visible facets of the lean can have a significant impact on quality of live at the social level and cause other additional problems like increased insecurity (crime and violence) or intra-family and psychological problems.

According to UNDP report, the impact of the crisis at the community level is stated that communities are directly affected by the crisis through a decline in production and employment. According to field data, the education rate has increased compared to past due to KKTE awareness program and special adult education project. The causes of non-enrolment are determined mostly by the degree of poverty and lack of awareness among the parents. Identifying and addressing the specific challenges facing the field is not an easy task. Yet there is much to be optimistic about.

According to recent research from the Rockefeller/Provence Fund Double Bottom Line Project, the social investment field - defined as early-stage double bottom line venture capital funds, socially responsible mutual funds, and high-engagement grant makers - has a total capitalization of at least $\$ 65.7$ billion. If even a small portion of these assets were marshaled and invested strategically, the potential impact for advancing the field and increasing social returns could be significant. Following lacks were recognized by the respondents: lack of school for child education; lack of hospitals in KKTE; lack of adult education facilities; lack of play ground; special fund for disable; ration provision for the workers; active role for social activities; need to improve community relations; need to be increased salary and wages for the staff and workers; full phase HR policy; benefits/donation for the poor. 


\section{Conclusion And Recommendations}

Impacts has created by the KKTE in various ways including social, economic and environmental. KKTE is the key stone in rural sandy zone of Panchagarh district by creating green carpet on the vast and fallow sandy areas.It also working for the rural poor people through the creation of employment opportunity especially for women. The disables, minority and ethnic people were getting preferences for the employment. In the conclusion the overall socio-economic condition of common people is changing rapid in Panchagarh following a faster development of the tea sector. Local tea growers elected body and officials concerned opined that setting up of more tea processing industries, competitive markets at the grass roots for tea leaves, supply of natural gas and resolving problems like power crisis could accelerate the production of tea. At the same time, hundreds of Panchagarh females, who lived in utter miseries due to abject poverty for years together, are now changing their fate and achieving self-reliance by earning wages as plucking workers in the dozens of tea gardens at the officially recognized third Tea Zone of the country. The female workers are yet to get their just wages from the garden-owners as the growing tea-farming sector in the region has been facing manifold problems including present unfair prices of the tea leaves for the tea farmers.

KKTE need to be run the pension system, medical insurance program for the staff \& workers, can advocate on social awareness program for organic cultivation and need to be develop written policy for staff welfare and CSR activities.

\section{References}

[1] Vivek Misra, Knowledge Manager, Centre for Good Governance

[2] Barrow, C. J. Social Impact Assessment: An Introduction. London, UK: Arnold Publishers, 2000.

[3] IAIA, 2003. International Principles for Social Impact Assessment. IAIA Special Publication Series No. 2, May 2003. International Association for Impact Assessment. Fargo, US.

[4] Yunus, Muhammad (2008), Creating a World Without Poverty: Social Business and the Future of Capitalism

[5] Burdge, R. J., Fricke, P., Finsterbusch, K., Freundenburg, W., Gramling, R.,Holden, A., Llewellyn, L., Petterson, J., Thompson, J., \& Williams, G. (1995).Guidelines and principles for social impact assessment: (InterorganizationalCommittee on Guidelines and Principles for Social Impact Assessment)

[6] Burningham, K. (1995). Attitudes, accounts and impact assessment. TheEditorial Board of The Sociological Review (pp. 100-122). (Oxford: BlackwellPublishers).

[7] Becker, Henk. Social Impact Assessment. London, UK: UCL Press Limited, 1997.

[8] Burdge, R. J. (2003). The practice of social impact assessment - background.Impact Assessment and Project Appraisal, June 2003, $84-88$.

[9] Cock, J. (1994). Sociology as if survival mattered. SA Sociological Review, 6(2),14-31.

[10] SROI Primer C2004 nefwww.neweconomics.org

[11] Brewer, J., \& Hunter, A. (1989). Multimethod Research: A Synthesis of Styles.(Newbury Park, California: Sage Publications).

[12] Patton, M. Q. (1990). Qualitative evaluation and research methods (2nd Ed).(Newbury Park, California: Sage Publications).

[13] Burgess, R. G. (Ed.). (1994). Studies in qualitative methodology Vol. 4 IssuesinQualitative Research. (Greenwich, Connecticut: Jai Press).

[14] Nau, D. S. (1995). Mixing methodologies: Can bimodal research be a viablepost-positivist tool?.The Qualitative Report, 2(3).

[15] Flick, U. (1998). An introduction to qualitative research. London: SagePublications.

[16] Taylor, C.N., Bryan, C.H. \& Goodrich, C.G. (1990). Social assessment:Theory, Process and Techniques. Studies in Resource Management No 7,(Centre for Research Management: Lincoln University, New Zealand).

[17] Durreen Shahnaz and Patricia Shu Ming Tan, 2011. Challenges and Opportunities in Social Impact Measurement for Asian Social Enterprises Experiences from Bangladesh and Thailand

[18] Annual Report 2010, Bangladesh Tea Board

[19] Bangladesh Sangbad Sangstha 